\title{
Facilitating Mobile Music Sharing and Social Interaction with Push!Music
}

\author{
Maria Håkansson, Mattias Rost, Mattias Jacobsson and Lars Erik Holmquist \\ Future Applications Lab, Viktoria Institute, Sweden \\ \{mariah, rost, majak, leh\}@viktoria.se
}

\begin{abstract}
Push!Music is a novel mobile music listening and sharing system, where users automatically receive songs that have autonomously recommended themselves from nearby players depending on similar listening behaviour and music history. Push!Music also enables users to wirelessly send songs between each other as personal recommendations. We conducted a two-week preliminary user study of Push!Music, where a group of five friends used the application in their everyday life. We learned for example that the shared music in Push!Music became a start for social interaction and that received songs in general were highly appreciated and could be looked upon as 'treats'.
\end{abstract}

\section{Introduction}

Today we are seeing tagging, blogging, sharing and recommending as increasingly adopted and popular phenomena on the internet. Media sharing and tagging sites like Flickr [10], social networks like Friendster [11] or MySpace [24], and social bookmarking systems like del.icio.us [6] are just a few examples of the ongoing trends. With the rapid development of networking mobile technologies, we are also starting to see mobile versions of these and similar systems. A wide variety of mobile social software is possible using the short-range communication and proximity- and location-sensing offered by mobile phones and other mobile technologies. We believe that there is a clear motivation to start looking into how these mobile versions could be designed and used.

In this project we have chosen to focus on music, which relates naturally to many social activities. Music is something we often consume, enjoy and create together, and it is an important means to create an identity and express ourselves among others [3, 7]. With new technology, the ways we manage, consume and create music have changed. The introduction of the Walkman, for example, allowed people to listen to

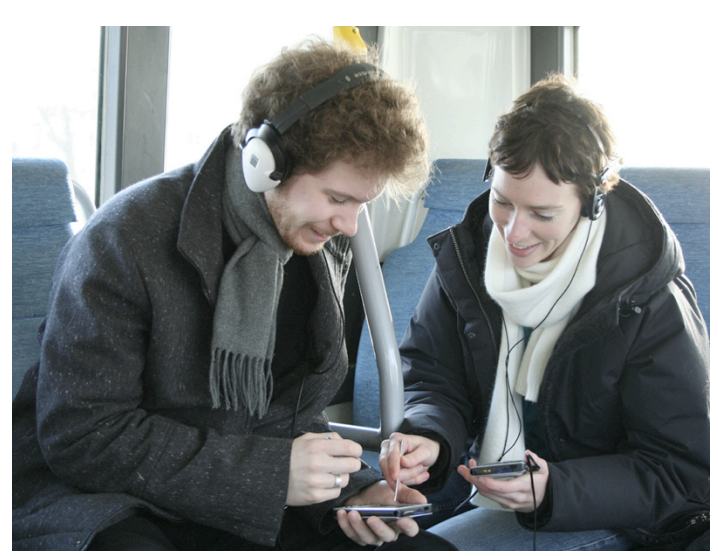

Figure 1. Push!Music is a mobile sharing system that lets users recommend and send music wirelessly to each other.

music everywhere but isolated from others [4]. Today the music listening and recommender system Last.fm [22] and Pandora [27] help us find more music, where Last.fm uses thousands of users' profiles and playlists to predict, based on what you already listen to, what you would like to hear next. There are thus already useful technologies that help us share or find music, but most of these are not mobile. They primarily support us when we are sitting at our computers at work or home, not when we are listening to music on the way to work or spending time somewhere else. Mobile music technology [14] is a growing field that explores, among other things, how mobile music listening and sharing can be turned into social experiences and trigger interaction between people in our everyday lives. For example, what would happen if the mobile MP3-player were augmented with networking and we could start sharing and recommending music on the move?

In this paper we introduce Push!Music (see Figure 1), a novel mobile music listening and sharing system that provides users with automatic recommendations, which are songs that autonomously copy themselves from nearby players based on implicit tagging information (e.g. similar listening behaviour and music 
history). Push!Music also enables users to wirelessly send songs between each others as personal recommendations. With this system we want to explore what would happen if we could share music with and recommend music to the people we meet in our everyday lives. Here we further present and discuss results from a preliminary two-week user study of Push!Music. The application was used by a group of friends to see how this means of sharing music (autonomous and personal) was experienced, and to test the prototype in use.

The outline of this paper is as follows. We first illustrate related work and the Push!Music application itself. We thereafter present the study and its results, before highlighting and discussing some of the findings.

\section{Related work}

Common for existing mobile social systems is that they rely on and benefit from peer-to-peer communication and ad hoc networking to detect nearby users and support social awareness in different ways. An early example of a mobile social software application is the Hummingbird [17], which used RFenabled GameBoy devices to alert users when others are nearby to support social awareness and collaboration. In Social Serendipity [9], users carry a Bluetooth-enabled mobile phone that detects other nearby users and triggers spontaneous face-to-face interaction with those who have similar user profiles. Finally, in the commercial system Dodgeball [8], users can send mobile phone messages about events to friends in their social network and get notifications whenever a friend or even a friend of a friend is in the vicinity.

A number of projects have begun exploring mobile music sharing systems, which build upon ideas from mobile social software like the ones mentioned above. Two systems, tunA [2] and SoundPryer [35], look at how the usually private listening of a mobile music device can be turned into a social experience by synchronising the listening to music between nearby devices. In tunA, music is streamed over an ad hoc network, allowing nearby users to "tune in" and eavesdrop on each other's devices as a means to create new types of social listening experiences. SoundPryer is similar, but allows people on the road in encountering vehicles to listen to each other's music. Both systems are implemented on PDAs and use wireless network with a shared radio model to allow users to listen to the same music in a synchronised way. In the stationary but related commercial music listening software iTunes [19], people located in e.g. the same workspace are able to share music by letting other users browse and listen to their playlists.

With the increasing amount of available music, users will likely at some point need guidance in what kind of music they would like, but do not already know. Recommender systems fundamentally build upon the notion of "automated word of mouth" [30], and support the way we usually appreciate and trust recommendations from friends or people with similar taste, when we are about to select and/or buy something. Recommender systems are also beginning to move from desktop PCs to mobile devices, where mobile recommender systems could provide more personal and even location-based recommendations, as opposed to internet-based services like Amazon [1], where recommendations are based on a large amount of anonymous people. Miller et al [23] explore how to turn recommender systems into mobile, personal, peerto-peer recommender systems in their PocketLens project. Another distributed mobile recommender system is MobiTip [28], where recommendations are transferred between users with similar interest and history as they meet.

Finally, as reported in a study of recommender systems vs recommendations from friends [31], systems and friends give different but complementing recommendations. In general, friends gave better recommendations than the systems in the study, but sometimes the systems gave fresh and unexpected recommendations, which friends were less able to. This shows that it is valuable to get inspiration from different directions when wanting to find something, such as new music.

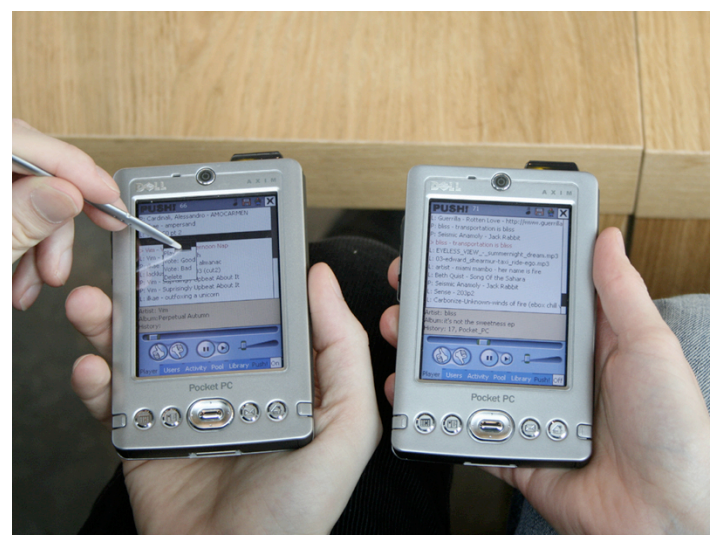

Figure 2. Push!Music currently runs on wireless ad hoc networking PDAs.

\section{The Push!Music system}

Push!Music is a mobile music listening and sharing application that detects nearby users and lets songs 
autonomously recommend themselves by copying from one mobile device to another [21], see Figure 2. It also lets users actively recommend ("push") songs to other users in an ad hoc wireless network. Early implications for design based on interviews with people interested in music, pointed at the potential value of having both personal recommendations and autonomous ones [18], similar to what Swearingen and Sinha reported in their study [31]. As opposed to [2] and [35] where the music is streamed, the music in Push!Music is copied between devices. Songs can therefore spread in a social network of music listeners as more people carry them.

When simply listening to music in Push!Music, songs are played randomly from the music collection stored on the mobile device. Whenever a song is recommended and sent to a player, it automatically enters the receiver's playlist as the next song to be played. Users have the option to explicitly rate songs, and songs with a higher rating are played more often, similar to the shuffle function in iTunes [19]. The songs also get implicit rating values as the user manages and listens to them. For instance, whenever a user skips a certain song, that song is rated lower at this point than if the song was listened to. This can be considered a form of implicit tagging of songs and provides input to determine which songs should autonomously copy and recommend themselves to other nearby users. That is, the tagging tells in which song context (playlist) a particular song is appreciated. Tagging of music can already be done in e.g. Last.fm [22], where users can decide themselves what they want to call the music they listen too. Although flexible, tagging music requires effort, which many users are still not prepared to give. In Push!Music, we are instead implicitly collecting equally valuable information, independently of music genres or users' own definitions.

\subsection{Interface and interaction}

The main view of the application is shown in Figure 3. The basic interface consists of standard playback control buttons, buttons for rating a song, a song history (displaying the four last nearby owners of the song being played), a volume control and a playlist. The playlist is the key part of the interface and is split in two parts, which are separated by a single field displaying the song currently being played. The top part displays a "history list" of songs that have been played and the bottom part displays a dynamic "future list" of songs to be played. It is in the future list that received new songs appear.

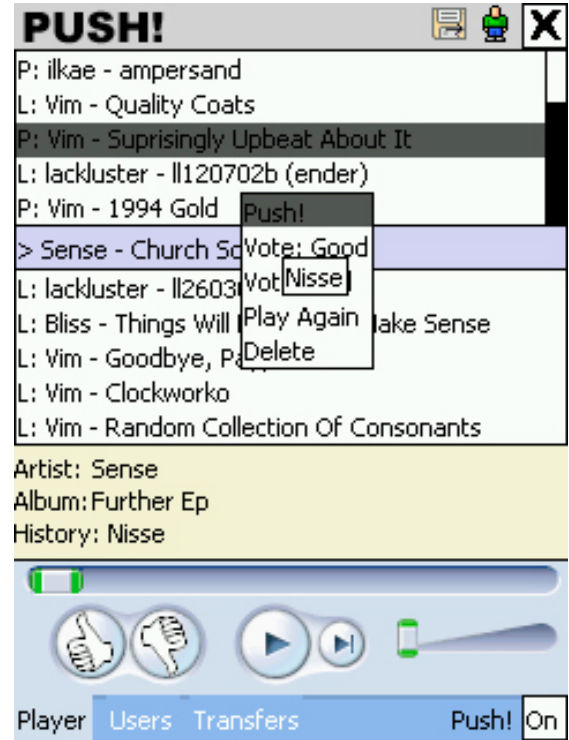

Figure 3. The Push!Music interface. The popup menu is visible, showing who you can currently push the song to.

When the user wants to push a song, he/she clicks on that song in the playlist. Only songs that have had a chance to be played and are in the history list can be sent to other users. From a popup menu, the user can then choose "Push", which reveals a new menu of nearby available users (see Figure 3). Selecting a user name initialise the song transfer. The popup menu also allows the user to play a song again, rate good/bad or delete a song.

The tabs at the bottom of the screen allow the user to flip between a number of views. The "Player" tab shows the main view with the playlist, the "Users" tab shows a list of users in the vicinity (listed by user names) and finally, the "Transfers" tab shows the status of any file transfers (uploads and downloads). The transfer list displays which songs are being transferred and whether they are personal recommendations or autonomous ones. For any song transfer, there is a progress bar displaying the percentage until completion. The playback control buttons are constantly visible to easily allow turning the music on/off and changing the volume.

The icons at the very top of the screen are provided to give the user some information at a glance: the image of a person indicate when other Push!Music users are in the proximity. The person turns green and waves his arms to notify when other devices are detected within the $\mathrm{WiFi}$ range, and when no one is nearby the person is red. The icon picturing a diskette notifies the user about any song transfers: an on-going up- or download is displayed with an arrow on top of 
the diskette. Both icons are clickable short cuts to their corresponding tabs.

Currently, we have chosen to show very little personal information about a user. Users are simply identified by nicknames, which they can choose themselves. In a study of tunA [2], the authors reported that users were somewhat unwilling to share personal information such as profiles with strangers. Since trust and privacy are critical aspects of social software and/or sharing systems, we feel that we need to conduct further studies before we include any more support for such information.

\subsection{Implementation details}

Push!Music runs on PocketPCs running Windows Mobile 2003 and equipped with built-in WiFi-cards $(802.11 \mathrm{~b} / \mathrm{g})$. The application is implemented in $\mathrm{C}++$ using GapiDraw [13] for graphics, and FMOD [12] for MP3-playback. Both GapiDraw and FMOD are cross platform compatible, which makes the application easy to port to a wide range of platforms. To be able to fit a reasonable amount of MP3-files, the PDAs were equipped with additional 1 GB SD-memory cards.

To enable wireless communication between devices there are essentially two options, Bluetooth and $\mathrm{WiFi}$, where we chose WiFi for two main reasons. Firstly, discovering peers in an ad hoc peer-to-peer manner is easier with WiFi than with Bluetooth. Secondly, WiFi offers faster transfer rates than Bluetooth. As the Push!Music application should be able to transfer rather large amounts of data, the transfer times become critical. The downside with WiFi compared to Bluetooth is currently the power consumption. However, technical achievements are already decreasing the power consumptions of WiFi close to that of, and even below, Bluetooth.

Push!Music thus utilises the built-in WiFi to connect in an ad hoc manner with other Push!Music devices. A basic discovery service was implemented to alert when two devices connect to each other, and it continuously broadcasts hello messages over UDP, as well as monitors a certain port to be alerted of hello messages from other devices. When such a messages is received, a TCP connection is established between the devices, over which communication occurs. When the connection is lost, the device is said to have disappeared. To make a quicker response when a device disappears, ping messages are sent when not communicating. If a transfer of a song is interrupted, the partially received music file is kept on the receiving device, and the transfer is resumed whenever the same song is pushed to that device again.
For the autonomous, spontaneous copying of songs, Push!Music uses an underlying concept of media agents [18], [20]. A media agent is an MP3-file that is augmented to constantly collect information about the songs it is being played with and the ratings (explicit and implicit) of these songs. By representing the music files as media agents and using ideas from collaborative filtering to create a distributed recommender system [20], the agents are triggered to copy themselves to other devices in the vicinity where they think they will be appreciated. As the agents carry their information with them, they accumulate the amount of data as they visit new devices and are thus able to make better and better predictions about which user will appreciate a song.

When devices meet, they immediately start to communicate and probe each other. The probing is done by sending media agent data (i.e. the actual data about the agent, without any music file) to each other. This data contains all information for computing the similarity of an agent with the other agents on the device. This similarity is the same as used in other common collaborative filtering algorithms (e.g. itemitem), but here used to compare agents. For details about the algorithm, see [20]. When a computation is complete, the response is sent back with a prediction on how well the agent fits the device's collection of media agents. The computations are thus performed on the receiving device. If the prediction is above a certain threshold, the song is pushed.

Finally, if the memory card gets full, the least popular songs in the current prototype will delete themselves to give space to new songs. These songs could for example be songs that have been rated bad several times and/or skipped repeatedly in the playlist.

\subsection{Copyright and payment}

Peer-to-peer file sharing inevitably brings up the question of payment and copyright models. It is clear that new models are necessary to facilitate not just our system, but for other innovative sharing systems as well. There are currently some suggestions of new models that are promising for systems like Push!Music. For example, Weedshare [34] looks at how peer-to-peer sharing can be legal and even encouraged, using a concept where the sender of a song earn a payment if the receiver chooses to buy the song that was sent to him. Creative Commons [5] looks at how copyright could be more flexible to suit various artists and purposes. Further possible solutions are subscription services (e.g. [26]), which offer an easy way of paying for unlimited amount of use for a limited period of time, and micro payments, which 
could be applied to e.g. each transfer of a song. Although Push!Music does not include any of the above mentioned solutions at the moment, it would be compatible with these models.

\section{Preliminary user study}

We conducted a preliminary user study in an everyday environment, which provided us with both qualitative and quantitative data about the application in use. Our goals with the study were to explore how this means of sharing music is experienced and used, and to test the application in use. When evaluating recommender systems, one can focus on different factors (such as the accuracy of the collaborative filtering algorithm). Among important evaluation criteria listed by [16], we chose to focus on the overall user satisfaction. As Push!Music is designed to provide new influences and inspiration, we believe it is more interesting to look at users' use and experiences, rather than to investigate how accurate the recommendations are.

The study involved a group of friends consisting of five male users aged 22-30, all with a wide-ranging interest in music. We considered them to be a suitable group to explore the social aspects of Push!Music, because they would meet daily during the week at the university where they study. They were each given a PDA with Push!Music installed and earphones. Before the study began, the participants had their PDAs filled with roughly 100 songs each, which they had individually selected among their own private music collections. They were not explicitly familiar with each other's music before the study.

The study ran for two weeks in October 2005. In a pre-study meeting, the participants were first introduced to the overall concept of Push!Music and the functionality of the application. We did not go into detail of the media agents, but explained that songs are able to move autonomously, depending on e.g. listening behaviour and rating. They were told to use Push!Music as they pleased, but were encouraged to use it as their main mobile music listening device during the study. They agreed to not change the music library on their device by adding or removing songs.

Qualitative data was gathered in a pre-study questionnaire on their interest in music, throughout the study in daily shorter feedback and support sessions, on a web forum where the participants had the option to post any spontaneous comments and most importantly, in a post-study focus group session with open-ended questions about the experience and use of Push!Music in the group. We met up with the participants in shorter feedback and support sessions every weekday during the study to check any technical problems. This usually involved taking a look at the ad hoc network settings. At the same time, we documented spontaneous comments and questions as well as our own observations by note taking. We posted a list of simple instructions (how to connect to the network) on the Push!Music forum, which they used throughout the study when we were not there to help them in person.

Quantitative data such as transfers of songs between devices and time spent connected to the ad hoc network was gathered by logging events in Push!Music. The media agents' individually collected information also provided us with log data.

\section{Results}

The participants used their Push!Music players during each weekday of the study, mainly at the university campus. They commonly worked around a large table with their laptops and their Push!Music players running, positioned next to the laptops. Earphones were connected but not always worn. Push!Music was also used as a more traditional music player when wanting to withdraw into, as one of the participants put it, your "own little world". Some of the participants did occasionally use Push!Music at the bus to/from university and at home.

All of the participants received new songs through Push!Music during the study - the number of new songs varied from 19-54, including both personal and autonomous recommendations. In general, they received more autonomous recommendations than personal ones.

\subsection{User experiences}

Below we present the qualitative results from the user study. All quotations are translated from the users' native language.

5.1.1. Received songs as 'treats'. The participants enjoyed sharing music with Push!Music - in particular when songs they did not know about or own, suddenly appeared on their devices:

"... I remember when I was sitting on the bus listening and then a new song appeared, which I had never heard before or knew what it was, that was good. And it simply popped up, I hadn't chosen it, but it simply appeared and I thought it was kind of good."

The group valued that they could recommend songs simply by sending them to someone nearby, but it was the autonomous recommendations of songs that got most of their attention. Receiving songs in general was 
highly appreciated and could be seen as obtaining some sort of 'treats'.

However, the participant had different opinions whether there was an added value in songs that had been recommended to you by a person, opposed to songs that had autonomously copied themselves to your player. One participant claimed that he appreciated a recommended song more, simply because he thought the sender would send him a carefully picked song, not just any song. Autonomously transferred songs, he claimed, could be just random. Another participant did not consider a difference in added value between the two ways of obtaining a song. To him, it was ultimately a matter of his taste in music that determined whether he would really appreciate the received song or not. During the study they all received songs they had not heard before and appreciated, as well as songs they had not heard before and did not like. In any case, they saw Push!Music as a potential and exciting way of breaking music listening habits.

We identified two slightly different motivations for pushing a song to another user. The first motivation could be called 'dissemination' - the sender liked a song and simply wanted others to hear it as well: "Well, you kind of thought like this... I like these songs and then they [the other participants] got to hear them too... or then they got to have them as well." The second one could be called a personal 'recommendation' - the sender sent a song that he believed a particular receiver would appreciate: "... at some point I sent some song because I thought that this person would surely like to hear this..."

The participants did not often ask directly for songs. Although this still happened occasionally during the study, it seemed as though the recommended and automatically received songs were satisfactory and almost 'covered the need' for new music. As two participants argued:

Participant 1: "I don't think we asked each other [for songs] much."

Participant 2: "No. You thought it was fun that it [music] turned up automatically."

\subsubsection{Shared music as a start for social interaction.}

Receiving new music spontaneously was thus highly appreciated in itself, but the sharing of music also triggered social interaction. The general opinion was that Push!Music was exciting and engaging when used together in the group, but less interesting when used alone. This was partly due to the preliminary interface of the prototype, but mostly because Push!Music was considered most interesting when "something was happening" in the playlist, that is, when songs were moving between players:
"If we all were there at school and listened to music then things were happening in the playlist... kind of unexpected things... some song from someone appeared... then things were really happening in the playlist... but... if you are at home, on the bus and don't have any of the others around, well, then it's kind of "oh, now THEY [the same songs] come again..."”

Push!Music was used actively in the group and involved more "play than listening". That is, the participants did not necessarily listen to music when sitting in the group, but they were nonetheless engaged in the sharing of songs. They monitored their PDAs frequently and switched views from the playlist, to the transfer list, to the list of online nearby users. This was one way to make sure that the devices were connected, but it was also clear that the participants enjoyed keeping track of what was happening in their Push!Music application. Ongoing activities such as transfers of songs triggered discussions in the group. For example, it was possible for them to see that a song is autonomously recommending itself to another user, but not to whom. The participants commented out loud on what was happening: "A Bruce Springsteen song is being sent to someone right now!"; "I'm sending [i.e. the device] something automatically now, who will get it?"

These discussions also applied to the personal recommendations sent among the participants. The quote below illustrates a playful approach to sending songs to people, where the user refers to sending a song back to the person who previously recommended him a song: "I counter by pushing [you] a..." However, sometimes the social interaction and the discussions about the sharing were not enough - one example of this is if someone sends a song and the receiver does not notice it until later. One participant explained to us that he had recommended a song to one of his friends, but despite the feedback from the application that the transfer was completed, he could not tell if the receiver had listened to it and what he had thought about it. As a recommender of a song, he understandably wanted to know what his friend had thought of it.

All in all, the participants seemed to have obtained a good picture of the songs - which ones had copied and which had not, and which songs they had received from whom. They enjoyed the song history information and were disappointed that, due to a technical error, it did not always work during the study:

"Even if you knew that this song had been played among [us], it didn't always show, [it was] simply empty in the history. But that was a pity. It would have been fun to sort of track your songs [and] stuff, where they came from. Because it was fun once you really saw that it was like three people who had had it. Then 
you kind of understood that it had been sent from there, to there and then to me."

It was clear that they still enjoyed the social awareness that the song history provided, despite the facts that they already knew each other and that the group was intimate. It was intriguing to know where a song came from, and this information was at some points also used in a more playful or even mischievous way to 'confront' the sender. One participant admitted rather awkwardly that he had personally recommended one song to another participant, and he was later quite taken aback by the consequences - more of similar songs were triggered to autonomously send themselves to the same receiver:

"it felt like maybe if I had sent something to $X$ by a certain artist, and he had got it, then it felt like no matter if he rated good or bad, he received lots, yes [from] that artist all the time. [laugh]"

This incident generated some jokes in the group about the sender's taste in music, since the participant who got the songs claimed he neither appreciated the first recommendation nor the songs that followed autonomously.

5.1.3. Gaming the system. Having a playful approach and 'gaming the system' was a way for the participants to gain an understanding of Push!Music and what triggered the songs to recommend themselves. The group developed different comprehensions of how they thought rating affected the songs, as well as various strategies on how to rate:

Participant 1: "Well, I tried to rate tactically every now and then. Let's say there were songs that you started to get tired of... then I... then I tried to rate them bad so that they would not turn up all the time. [...] And songs that you really wanted would send [themselves] you tried to rate good as well"

Participant 2: "Yeah, that's true! You weren't just thinking that you wanted to hear them yourself, you thought perhaps someone else wants to hear these and then you rated them..."

Participant 1: “...good ..."

They essentially developed rating strategies to affect either which songs they wanted to listen to, or which songs they wanted should autonomously copy and move to the others' players. The latter was a matter of trying to stimulate songs to move, which seemed to be done as much of tactics as of curiosity of seeing how Push!Music works: "When I rate songs that I have received, things start to happen." One of the participants had three children's songs on his device, which evoked great excitement when he revealed this to the others. Throughout the study, the other four kept asking him to push the songs to them, but he refused. He explained that he did not want to recommend the songs himself, but wanted to wait cunningly to see if and when they would copy autonomously to the other players. However, each time they were played on his device, he rated them good to encourage any future actions.

5.1.4. Push!Music in the future. The participants reflected on what they imagine future use of Push!Music could be like. They all agreed that Push!Music has great potential as a means to get in touch with new music through friends and the people you meet. For example, one participant pictured himself meeting friends for a coffee and at the same time getting their latest favourite songs. Another participant imagined walking around in the city, "harvesting" new songs. They all liked the idea that with Push!Music, you might not have to update your playlist as frequently as today.

However, they also brought up less pleasant scenarios such as receiving spam, commercials or simply an overflow of songs. They suggested that the autonomous sharing of songs is something that should be possible to turn on or off, simply because you are not always in the mood for getting inspiration to listen to new music. They were concerned that receiving songs from strangers could be awkward simply because of the dynamic nature of the ad hoc network. If you wanted the entire song being transferred to you, they pictured you would have to "stick around" the sender until the transfer was complete.

\section{Interface re-design}

We have chosen to address a number of issues regarding the user interface, which were discovered during the study. These mainly had to do with the participants' concerns about a limited user control when choosing which songs to play and to push, and which ones to receive. In comparison with commercial MP3-players, they also experienced the interface in Push!Music as somewhat limited, which made it less fun to use the application in the quality of a "regular" music player.

In the re-design of the interface (see Figure 4), the main goal has therefore been to increase the user control but make sure that the implicit listening behaviour can still be collected. The previously split playlist has now been replaced with a more conventional playlist that displays all songs in one list. Users are further able to manipulate the playlist as they please, by adding or removing songs. In the new version, any song can be pushed from the playlist. The act of pushing is the same, but all transferred songs (pushed or autonomous) are temporarily placed in a 


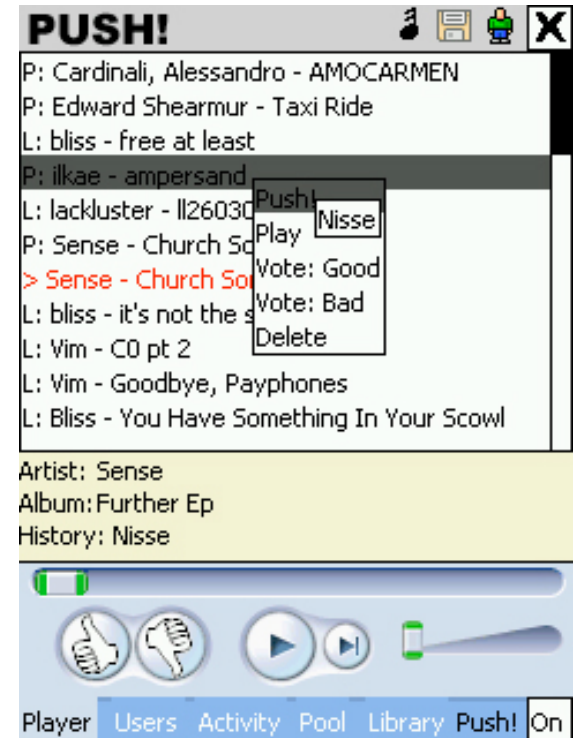

Figure 4. The new re-designed interface enables more user control.

pool of songs before they enter the playlist as next songs to be played. The motivation behind the pool is to give users a better overview of incoming songs and a chance to postpone such listening until later. We have also added more information in the transfer list. Along with the existing information on whether a song is pushed or autonomously copied, one can now also see from whom a song is being sent (only nickname is displayed).

\section{Discussion}

Below we will discuss and highlight some of the results, as well as introduce a number of questions that require further exploration.

The participants enjoyed Push!Music because they could send music directly to someone as a recommendation and because songs were autonomously sending themselves between players. One possible reason why the participants liked receiving both the personally recommended and the autonomous songs, could be that one could look at these received songs as 'treats'. This is similar to how text messages were seen as gifts in Taylor and Harper's study of teenagers' use of mobile phones [32]. Receiving new songs was exciting and often unexpected. Moreover, the autonomous songs generated surprise not only for the receiver but also for the sender: a song is copying itself from my player, whom will get it?

The social presence of the other users contributed to making the Push!Music player exciting and fun. Activities such as sending someone a song, monitoring the PDAs to see things happening, guessing from whom a song was sent or being sent to and occasionally asking for songs, generated discussions and a sense of a connection among the participants. In Push!Music, the shared music thus became a start for social interaction, as O'Hara et al. [25] observed in their study of Jukola, a democratic jukebox system at a café bar. In their study, varying groups of people would discuss and collaboratively nominate songs they wanted to hear playing at the place. This also triggered people to guess group belongings, create strategies when voting and engage in friendly competitions about "winning" songs. Like in the study of Jukola, we also noted that the participants came up with playful or cunning approaches when managing the music sharing.

As Voida et al [33] observed in a study of iTunes music sharing, people made an effort to select music that would create the identity they wanted. This could for example imply that people enhanced their music collections to reflect a more "balanced" image of themselves, or that people wanted their music collections to reflect a deep knowledge in a particular artist or genre. Goffman [15] called this phenomenon impression management, which appears not only in iTunes music sharing but also in the use of Push!Music in the group. However, in Push!Music, the participants discovered a dilemma regarding their impression management - not only the songs that create the "right" image about the sender were able to autonomously recommend themselves, but any of their songs. For example, one participant personally recommended a song to another participant and was quite taken aback when several other songs thereafter autonomously copied themselves to the same person: songs he had not planned to send or even wanted to send. On the other hand, could the dynamic and everchanging playlist (or collection of music) in Push!Music have an affect on what we define as our music identity? As opposed to peoples' playlists in e.g. iTunes [33], which will not change unless the owner decides to do so, the playlists in Push!Music will over time consist of music from many different users. Would this give a new meaning to the personally selected playlist or personal soundtrack?

Finally, when talking about the music sharing during the study, the participants also frequently mixed the notion of devices (or rather media agents) and users: they could say that they (as persons) were sending a song when in fact it was the players or the media agents that did this autonomously. A similar thing was also observed in a study of mobile ad hoc networking games [29]. An interesting question related to this is if one could feel a sense of responsibility for what one's Push!Music player is doing, although it, according to one participant "lives its own life"? 


\section{Conclusions and future work}

With Push!Music, we have shown a novel way of wirelessly sharing music with the people you encounter in your everyday life and get inspiration from the persons who have a similar "taste" in music. A mobile music sharing system could be more spontaneous and serendipitous than a stationary one, meaning that you could share music with the people you encounter, as you are listening to it on the move - you would not have to wait until you are back at the computer at home or at work. With a mobile system we could also explore taking advantage of the dynamics and personalities of physical places - imagine going from neighbourhood to neighbourhood and receiving varying music of all kinds.

Although preliminary, we believe that our user study points out both potentials and challenges with these kinds of mobile media sharing systems. In the study, we learned that the users enjoyed receiving autonomously transferred songs as a way of getting new music influences. They also appreciated being able to send songs to each other, and had different motivations for doing so. However, they were also concerned what would happen if you received simply too many songs, and suggested that the autonomous sharing of songs is something that should be possible to turn off.

The next step is to conduct a larger study where we want to involve people who do not know each other beforehand, to explore how such a critical factor could affect the sharing of music in Push!Music. Would people push songs to strangers? How would they relate to the fact that songs from their own players can move autonomously to any other nearby user's player? Maybe not all songs should be able to copy and transfer, but only specific music chosen by a user? Further, would users be willing to share personal information such as a user profile or a picture with anyone?

Sharing TV shows, photos, blogs, movies, etc. on the internet is becoming increasingly popular. Mobile sharing of these kinds of media could be different than simply sharing content with anyone. For example, as we have shown in Push!Music, it could mean that we only share with people we actually meet. In Push!Music, users are primarily distributors of media, whereas if we look at blogs or media sharing sites like Flickr [10], users are also producers of media. How would such a factor affect mobile peer-to-peer media sharing and the design of these systems? How could users find the media they want in such mobile system? Another possible direction to take in this project is therefore to explore other types of media, such as photos, in combination with the concept of media agents, tagging and mobile sharing. We believe that mobile peer-to-peer sharing has many interesting future uses and that Push!Music and our study of it have started pointing towards the potentials and challenges of such systems.

\section{Acknowledgements}

We would like to thank Barry Brown and colleagues at the Viktoria Institute and in the Mobile Life project for valuable comments on earlier drafts, and the study participants for their time and enthusiasm. This work is supported by the ECAgents project (IST-2003-1940) funded by the European ISTFET programme.

\section{References}

[1] Amazon: http://www.amazon.com

[2] A. Bassoli, J. Moore, and S. Agamanolis. "tunA: Local Music Sharing with Handheld Wi-Fi Devices". In Proc of 5 th Wireless World Conference 2004, Surrey, UK.

[3] B. Brown, A. Sellen, and E. Geelhoed. "Music sharing as a computer supported collaborative application". In Proc of the ECSCW 2001. Dordrecht: Kluwer Academic Publishers, pp.179-198.

[4] M. Bull. Sounding Out The City, Berg, NY, 2000.

[5] Creative Commons: http://creativecommons.org/

[6] del.icio.us: http://del.icio.us/

[7] T. DeNora. Music in Everyday Life. Cambridge University Press, Cambridge, 2000.

[8] Dodgeball: http://www.dodgeball.com/

[9] N. Eagle and A. Pentland. "Social Serendipity: Mobilizing Social Software". IEEE Pervasive Computing, vol. 4, no. 2, 2005, pp. 28-34.

[10] Flickr: http://www.flickr.com/

[11] Friendster: http://www.friendster.com/

[12] FMOD: http://www.fmod.org/

[13] GapiDraw: http://www.gapidraw.com/

[14] L. Gaye, L.E. Holmquist, F. Behrendt, and A. Tanaka. "Mobile Music Technology: Report on an Emerging Field". In Proc of NIME 2006, Paris, France. 
[15] E. Goffman. The Presentation of Self in Everyday Life. New York: Anchor Books, 1959.

[16] J. Herlocker, J. Konstan, L. Terveen, and J. Riedl. "Evaluating Collaborative Filtering Recommender Systems". ACM Transactions on Information Systems 22 (2004), ACM Press, 5-53.

[17] L.E. Holmquist, J. Falk, and J. Wigström. "Supporting Group Collaboration with Interpersonal Awareness Devices". Personal Technologies, vol. 3, nos. 1-2, 1999, pp. 105-124.

[18] M. Håkansson, M. Jacobsson, and L.E. Holmquist. "Designing a Mobile Music Sharing System Based on Emergent Properties". In Proc of AMT 2005, Takamatsu, Japan.

[19] iTunes: http://www.apple.com/itunes/

[20] M. Jacobsson, M. Rost, and L.E. Holmquist. "When Media Gets Wise: Collaborative Filtering with Mobile Media Agents". In Proc of IUI 2006. Sydney, Australia.

[21] M. Jacobsson, M. Rost, M. Håkansson, and L.E. Holmquist. "Push!Music: Intelligent Music Sharing on Mobile Devices". In Adjunct Proc of UbiComp 2005, Tokyo, Japan. (demo)

[22] Last.fm: http://www.last.fm/

[23] B.N. Miller, J.A. Konstan, and J. Riedl. "PocketLens: Toward a personal recommender system". ACM Trans. Inf. Syst. 22, 3 (Jul. 2004), 437-476.

[24] MySpace: http://www.myspace.com/

[25] K. O’Hara, M. Lipson, M. Jansen, A. Unger, H. Jeffries, and P. Macer. "Jukola: Democratic Music Choice in a Public Space". In Proc of DIS2004. Cambridge, MA, USA.
[26] Napster: http://www.napster.com/

[27] Pandora: http://www.pandora.com/

[28] Å. Rudström, M. Svensson, R. Cöster, and K. Höök. "MobiTip: Using Bluetooth as a Mediator of Social Context". In Adjunct Proc. of Ubicomp 2004, Nottingham, UK.

[29] J. Sanneblad and L.E. Holmquist. "“Why is everyone inside me?!" Using Shared Displays in Mobile Computer Games". Entertainment Computing - ICEC 2004: Springer, pp. $487-498$

[30] U. Shardanand, and P. Maes. "Social Information Filtering: Algorithms for Automating "Word of Mouth"”. In Proc. of CHI 95, Denver, Colorado, USA.

[31] K. Swearingen and R. Sinha. "Interaction Design for Recommender Systems". In Proc. of DIS 2002. London, UK.

[32] A.S. Taylor and R. Harper. "Age-old Practices in the 'New World': A study of gift-giving between teenage mobile phone users." In Proc. of CHI 2002. Minneapolis, USA.

[33] A. Voida, R.E. Grinter, N. Ducheneaut, W.K. Edwards, and M.W. Newman. "Listening in: Practices surrounding iTunes music sharing". In Proc. of CHI 2005. Portland, Oregon, April 2-7. New York: ACM Press, pp. 191-200.

[34] Weedshare: http://www.weedshare.com

[35] M. Östergren, and O. Juhlin. "Car Drivers using Sound Pryer - Field Trials on Shared Music Listening in Traffic Encounters". In Kenton O'Hara and Barry Brown (eds.), Consuming Music Together: Social and Collaborative Aspects of Music Consumption Technologies. Springer, 2006, pp. 173-190. 